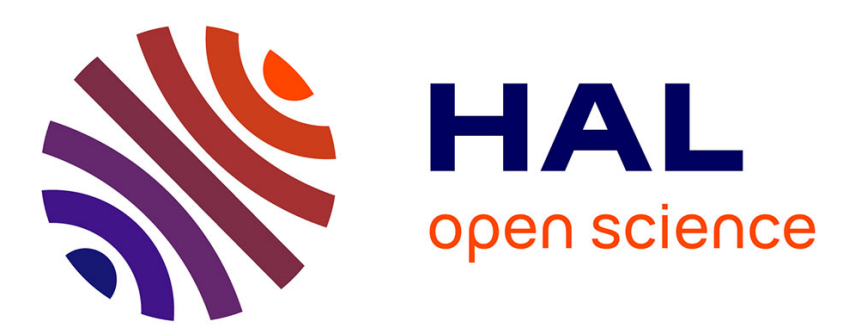

\title{
Heterogeneous Sodium-Manganese Oxide Catalyzed Aerobic Oxidative Cleavage of 1,2-Diols
}

\author{
Vincent Escande, Chun Ho Lam, Philip Coish, Paul Anastas
}

\section{To cite this version:}

Vincent Escande, Chun Ho Lam, Philip Coish, Paul Anastas. Heterogeneous Sodium-Manganese Oxide Catalyzed Aerobic Oxidative Cleavage of 1,2-Diols. Angewandte Chemie International Edition, 2017, 56 (32), pp.9561-9565. 10.1002/anie.201705934 . hal-01939564

\section{HAL Id: hal-01939564 \\ https://hal.umontpellier.fr/hal-01939564}

Submitted on 17 Feb 2021

HAL is a multi-disciplinary open access archive for the deposit and dissemination of scientific research documents, whether they are published or not. The documents may come from teaching and research institutions in France or abroad, or from public or private research centers.
L'archive ouverte pluridisciplinaire HAL, est destinée au dépôt et à la diffusion de documents scientifiques de niveau recherche, publiés ou non, émanant des établissements d'enseignement et de recherche français ou étrangers, des laboratoires publics ou privés. 


\title{
Heterogeneous Sodium-Manganese Oxide Catalyzed Aerobic Oxidative Cleavage of 1,2-Diols
}

\author{
Vincent Escande ${ }^{+}$* Chun Ho Lam ${ }^{+}$, Philip Coish, and Paul T. Anastas*
}

\begin{abstract}
The aerobic oxidative cleavage of 1,2-diols using a heterogeneous catalyst only based on earth-abundant metals manganese and sodium is reported for the first time. This reusable catalyst cleaves a variety of substrates into aldehydes or ketones with high selectivity. The reaction requires small catalytic loadings and is performed under mild conditions using ambient pressure $\mathrm{O}_{2}$ or air as the oxidant while producing water as the only by-product. Mechanistic investigations reveal a monodentate, two-electron oxidative fragmentation process involving a Mn ${ }^{I V}$ species. The eco-friendly, innocuous catalyst is compatible with a wide range of functional groups and conditions, making it highly competitive with classical reagents, such as periodic acid or lead tetraacetate, as a preferred method for activated 1,2-diols.
\end{abstract}

$T_{\mathrm{h}}$ ketones is an important transformation in synthetic organic chemistry. Since its discovery in the early 20 th century, ${ }^{[1]}$ this reaction has been employed in numerous applications ranging from organic syntheses ${ }^{[2]}$ to analytical studies in biochemistry. ${ }^{[3]}$ Recently, the oxidative cleavage of 1,2-diols has been employed in biomass valorization for renewable feedstock production. ${ }^{[4]}$ However, despite human health and environmental concerns, the reaction conditions continue to use the same archetypal reagents, periodic acid and its salts, and lead tetraacetate. While these reagents are known to be selective and efficient, their intrinsic toxicities and safe disposal are non-trivial consequences, questioned by sustainability standards. $^{[5]}$ Although several methods have been developed to address the aforementioned challenges using chemically benign oxidant, such as $\mathrm{O}_{2}$ or hydrogen peroxide, ${ }^{[2 a, 6]}$ they either require toxic reagents or high loadings of precious

[*] Dr. V. Escande, ${ }^{[+]}$Dr. C. H. Lam, ${ }^{[+]}$Dr. P. Coish, Prof. Dr. P. T. Anastas Center for Green Chemistry \& Green Engineering

Yale University

New Haven, CT 06520 (USA)

E-mail:vincent.escande@yale.edu paul.anastas@yale.edu

Dr. V. Escande ${ }^{[+]}$

Laboratory of Bio-Inspired Chemistry and Ecological Innovations, ChimEco, UMR 5021 CNRS-UM

34790 Grabels (France)

Prof. Dr. P. T. Anastas

School of Forestry and Environmental Studies, and Department of Chemistry, Yale University

New Haven, CT 06511 (USA)

$\left.{ }^{+}\right]$These authors contributed equally to this work. metals for the transformation. Driven by the need for sustainable catalysts, metal-free routes have been reported recently, ${ }^{[7]}$ as well as catalysts based on more abundant metals, such as complexes of $\mathrm{Fe},{ }^{[8]} \mathrm{Mn},{ }^{[9]} \mathrm{Ti},{ }^{[10]}$ and $\mathrm{V} \cdot{ }^{[11]}$ However, in addition to a frequent lack of selectivity, a critical drawback persists as most of these catalysts are homogeneous and nonrecyclable. Therefore, development of a cost-effective, innocuous, heterogeneous catalyst that enables a highly selective aerobic oxidative cleavage of 1,2-diols is imperative.

Our recent reports using catalysts prepared from Mn-rich plant extracts ${ }^{[12]}$ prompted us to investigate the utilization of a well-defined heterogeneous $\mathrm{Mn}$ oxide catalyst for the oxidative cleavage of 1,2-diols. Transition-metal oxides have attracted growing interest for the synthesis of small molecules. They represent a major class of heterogeneous catalysts used in industry. ${ }^{[13]}$ Among them, manganese oxides are particularly attractive for its abundance and low toxicity. ${ }^{[14]}$ These materials exist as a variety of structures, with unique catalytic properties in a number of reactions. ${ }^{[15]}$ In particular, in layered oxides such as birnessite, edge-shared $\mathrm{MnO}_{6}$ units form a lattice with exchangeable oxygen molecules. Mn species exist in the lattice as the mixed oxidation states $\mathrm{Mn}^{\mathrm{II}}, \mathrm{Mn}^{\mathrm{III}}$ and $\mathrm{Mn}^{\mathrm{IV}} \cdot{ }^{[16]}$ We envisaged the coexistence of these different oxidation states and the possibility of redox cycling with $\mathrm{O}_{2}$ would make Mn layered mixed oxide a good candidate for the aerobic oxidative cleavage of 1,2-diols as a heterogeneous catalyst. It is worth noting that activated manganese dioxide has been described as an efficient reagent for 1,2-diol oxidation but only with the use of a large excess of reagent [40:1 ratio of reagent:substrate]. ${ }^{[17]}$ While this amount of reagent has presumably disqualified the method as a feasible method for large-scale reactions, no catalytic version has been proposed so far.

Herein, we describe an unprecedented protocol for aerobic oxidative cleavage of 1,2-diols into aldehydes or ketones using manganese layered mixed oxide (Mn LMO) as the catalyst (Scheme 1). The absence of toxic solvents or reagents, the use of mild reaction conditions and the ability to cleave a variety of 1,2-diols within short reaction times by using $\mathrm{O}_{2}$ or air as oxidants are significant advantages of the method. Most importantly, the catalyst is easily prepared from inexpensive reagents and can be recycled multiple times without losing activity which makes this approach competitive with previous systems.

We prepared Mn LMO under mild conditions, adapted from a previous route. ${ }^{[18]}$ Oxidation of $\mathrm{Mn}^{2+}$ ions from $\mathrm{MnCl}_{2} \cdot 4 \mathrm{H}_{2} \mathrm{O}$ with hydrogen peroxide in presence of sodium hydroxide afforded the corresponding catalyst which was isolated by filtration. Energy-dispersive X-ray (EDX; Figure S1 in the Supporting Information) spectroscopy revealed 


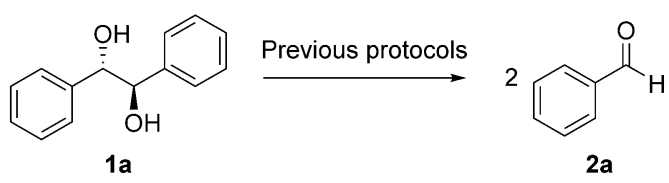

- Stoichiometric: toxic reagents and by-products, harsh conditions

- Catalytic: precious metals, additives or non-recyclable

This work:<smiles>O[C@H](c1ccccc1)[C@H](O)c1ccccc1</smiles>

1 a

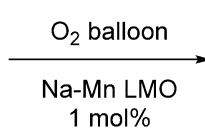

$1 \mathrm{~mol} \%$

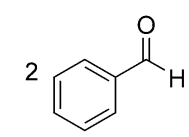

$2 \mathbf{a}$
- Heterogeneous, easily recyclable catalyst

- Earth abundant metals and $\mathrm{O}_{2}$

- $\mathrm{H}_{2} \mathrm{O}$ only by-product

Scheme 1. Previous routes and this work.

the oxide nature of the material, and presence of $\mathrm{Na}$ along with $\mathrm{Mn}$. Further characterization by inductively coupled plasma atomic emission spectroscopy (ICP-AES; Table S1) and thermogravimetric analysis (TGA; Figure S2) indicated that the material can be formulated as $\mathrm{Na}_{0.274} \mathrm{MnO}_{2} \cdot 6 \mathrm{H}_{2} \mathrm{O}$, hereafter referred to as Na-Mn LMO. Based on this composition, $\mathrm{Mn}$ is present with an average oxidation state of approximately $+3.7,{ }^{[19]}$ which was confirmed by X-ray photoelectron spectroscopy (XPS; Figures S3 and S4). Whereas Na-Mn LMO appeared to be of low crystallinity, its X-ray powder diffraction (XRPD; Figure S5) pattern showed prominent (001) peaks suggesting that Mn oxide layers are uniformly stacked in the birnessite phase with interlayered $\mathrm{Na}^{+}$ions. ${ }^{[20]}$ This is confirmed by Fourier transform infrared (FTIR; Figure S6) spectroscopy which displayed a strong band at $400 \mathrm{~cm}^{-1}$, characteristic of layered Mn oxides. ${ }^{[21]}$

We evaluated the performance of our Na-Mn LMO material as a catalyst for oxidative cleavage using mesohydrobenzoin under the atmospheric pressure of $\mathrm{O}_{2}$ in a model reaction. The exploratory conditions and results are presented as supplementary material in Table S2. The optimized reaction conditions afforded the desired product, benzaldehyde, in high yield. At $100^{\circ} \mathrm{C}$ in 1-butanol, a $99 \%$ conversion with complete selectivity toward benzaldehyde was obtained in $1 \mathrm{~h}$, with only $1 \mathrm{~mol} \%$ of Mn (Table 1 , entry 1). A high turnover frequency (TOF) of $180 \mathrm{~h}^{-1}$ at $100^{\circ} \mathrm{C}$ was achieved in the initial hour (see Supporting Information). While $\mathrm{O}_{2}$ gave the shortest reaction times, the same conversion was obtained in air, in $4 \mathrm{~h}$ (Table 1, entry 2). Control experiments under $\mathrm{N}_{2}$ confirmed the critical role of oxygen for the reaction (Table 1 , entry 3 ).

Only $5 \%$ yield was obtained with commercial $\mathrm{MnO}_{2}$ and activated $\mathrm{MnO}_{2}$, supporting the notion that the unique layered structure of $\mathrm{Na}-\mathrm{Mn} \mathrm{LMO}$ was critical to catalytic activity (Table 1, entries 4-5). Interestingly, a Na-birnessite similar to Na-Mn LMO but prepared in less-basic conditions gave a lower conversion (33\%) than Na-Mn LMO (Table 1, entry 6). While this result confirmed that a layered structure
Table 1: Oxidative cleavage of meso-hydrobenzoin catalyzed by $\mathrm{Na}-\mathrm{Mn}$ LMO and other Mn oxides. ${ }^{[a]}$
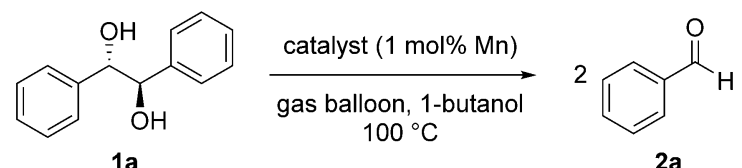

$\mathbf{2 a}$

\begin{tabular}{|c|c|c|c|c|c|}
\hline Entry & Catalyst & Atmosphere & $t[\mathrm{~h}]$ & $\begin{array}{l}\text { Conversion } \\
{[\%]^{[b]}}\end{array}$ & $\begin{array}{l}\text { Selectivity } \\
{[\%]^{[b, c]}}\end{array}$ \\
\hline 1 & $\begin{array}{l}\mathrm{Na}-\mathrm{Mn} \\
\mathrm{LMO}\end{array}$ & $\mathrm{O}_{2}$ & 1 & 99 & $>99$ \\
\hline 2 & $\begin{array}{l}\mathrm{Na}-\mathrm{Mn} \\
\mathrm{LMO}\end{array}$ & air & 4 & 99 & $>99$ \\
\hline 3 & $\begin{array}{l}\mathrm{Na}-\mathrm{Mn} \\
\text { LMO }\end{array}$ & $\mathrm{N}_{2}$ & 1 & $<1$ & - \\
\hline 4 & $\mathrm{MnO}_{2}$ & $\mathrm{O}_{2}$ & 1 & 5 & $>99$ \\
\hline 5 & $\begin{array}{l}\mathrm{MnO}_{2} \\
\text { (activated) }\end{array}$ & $\mathrm{O}_{2}$ & 1 & 5 & $>99$ \\
\hline 6 & $\begin{array}{l}\mathrm{Na}- \\
\text { birnessite }{ }^{[\mathrm{d}]}\end{array}$ & $\mathrm{O}_{2}$ & 1 & 33 & $>99$ \\
\hline
\end{tabular}

[a] Reaction conditions: meso-hydrobenzoin (42.9 mg, $0.2 \mathrm{mmol})$, catalyst (1 mol\% Mn), 1-butanol (1 mL), gas balloon, $100^{\circ} \mathrm{C}$. [b] Conversion and selectivity were determined by GC using dodecane as internal standard. Remaining mass balance is recovered starting materials. [c] Ratio of benzaldehyde yield to conversion as a percentage. [d] $\mathrm{Na}$ birnessite prepared according to Ref. [18].

was a key parameter for catalysis, it also highlighted the importance of basicity during catalyst preparation.

The base influence on catalyst morphology and activity was assessed by the preparation of catalysts within a range of $\mathrm{NaOH}$ concentrations (in excess relative to the amount required for oxidation of $\mathrm{Mn}^{2+}$ by $\mathrm{H}_{2} \mathrm{O}_{2}$ ). The resulting catalysts displayed increasing activity with increasing $\mathrm{NaOH}$ concentration up to an optimal concentration of $1.8 \mathrm{M}$ (Table S3) while average size of particles as measured by scanning electron microscopy (SEM) decreased to $4.9 \mu \mathrm{m}$. However, when the concentration of $\mathrm{NaOH}$ reached beyond this limit, average particle size increased dramatically to over $30 \mu \mathrm{m}$ along with an apparent decline in catalytic activity (Figure 1a).

These observations are consistent with the known influence of basicity on the crystallization of birnessite-materials. ${ }^{[22]}$ Indeed, when we examined a weaker base, tetramethylammonium hydroxide (TMA.OH) and stronger base, cesium hydroxide, we observed an optimal yield with $\mathrm{NaOH}$ (Figure 1b). Again, SEM measurements showed that excessively high basicity caused the crystallization of the material, resulting in the formation of large particles $(>30 \mu \mathrm{m})$ with low catalytic activity (Figure S7).

Using the most active form of Na-Mn LMO catalyst, a variety of 1,2-diols were readily cleaved under the optimized conditions (Table 2). Although $1 \mathrm{~mol} \%$ of Mn was sufficient to cleave these substrates, we selected $10 \mathrm{~mol} \%$ since it provided shorter reaction times. Both syn and anti as well as symmetrical and asymmetrical benzylic diols were cleaved efficiently (Table 2, entries 1-5). The applicability of the method was illustrated by high, isolated yields (up to $96 \%$ ), after simple filtration then evaporation of the solvent (Table 2, entries 1,3). Benzylic or allylic 1,2-diols were the 

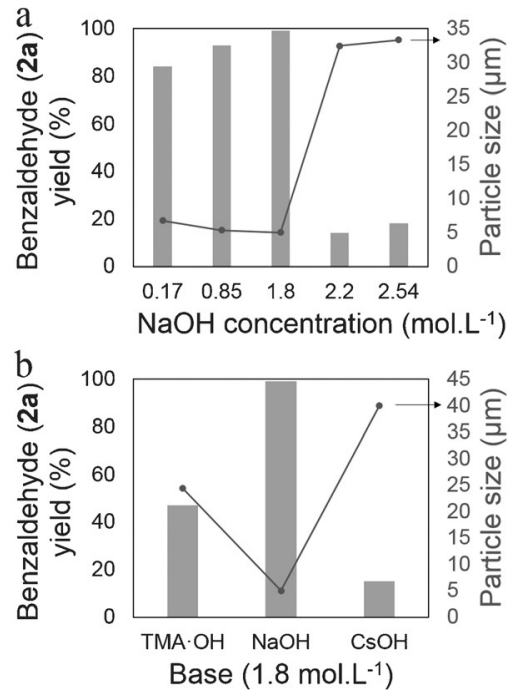

Figure 1. a) Influence of $\mathrm{NaOH}$ concentration used for $\mathrm{Na}-\mathrm{Mn} \mathrm{LMO}$ preparation on its catalytic efficiency and on particles size. b) Influence of bases of different strength on catalytic efficiency and on particles size. Reaction conditions for (a) and (b) are the same than for Table 1, entry 1.

most reactive, but the method was also efficient on less activated benzylic-aliphatic diols (Table 2, entries 5,6). In the particular case of a non-substituted 1,2-diol such as $\mathbf{1 f}$, the reaction was slower and some degradation occurred after long heating. However, addition of a base made the oxidative cleavage possible. A screening of bases (Figure S8) revealed that the mild base $\mathrm{Na}_{2} \mathrm{CO}_{3}$ was most effective. However, no reaction occurred on diols substituted by two aliphatic moieties (Table 2, entries 13,14), showing the catalyst was selective toward diols with a least one activating substituent. The Na-Mn LMO catalyst cleaved heterocyclic 1,2-diols with high efficiency (Table 2, entries 8,9), sometimes with only $1 \mathrm{~mol} \%$ of Mn, without any poisoning effect of the heterocyclic atom. Moreover, reactions were unaffected by the presence of electron- donating and withdrawing aromatic substituents, consistently achieving complete conversion with over $99 \%$ selectivity (Table 2, entries 10-12). Interestingly, a test on $(S)$-mandelic acid showed that the oxidative cleavage was also possible on this $\alpha$-hydroxy acid, here again with a beneficial effect of additional $\mathrm{Na}_{2} \mathrm{CO}_{3}$ (Table S4).

In addition to substrate surveying, kinetic experiments were devised to gain mechanistic insight. Interestingly, kinetic comparison of meso- and $(R, R)$-hydrobenzoin cleavage revealed the anti isomer, meso-hydrobenzoin, was cleaved faster than the syn isomer, $(R, R)$-hydrobenzoin (Figure $\mathrm{S} 9$ ). Such observation disapproved the cyclic type I mechanism, [2a] where the opposite trend would be expected. ${ }^{[17,23]}$ Moreover, in a cyclic type I mechanism, the reaction has usually second order (with order one with respect to the substrate and one to the oxidant). ${ }^{[2]}$ However, our initial rate kinetic study revealed the order with respect to meso-hydrobenzoin to be zero (Figure S10), and displayed a fractional order with respect to the oxidant (Figure S11). We therefore postulate the cleavage proceeded through a type II mechanism wherein an acyclic monodentate complex intermediate was formed as shown in Scheme 2. In this mechanism, the anti-diol would go

Table 2: Aerobic oxidative cleavage of 1,2-diols catalyzed by Na-Mn LMO.[a]

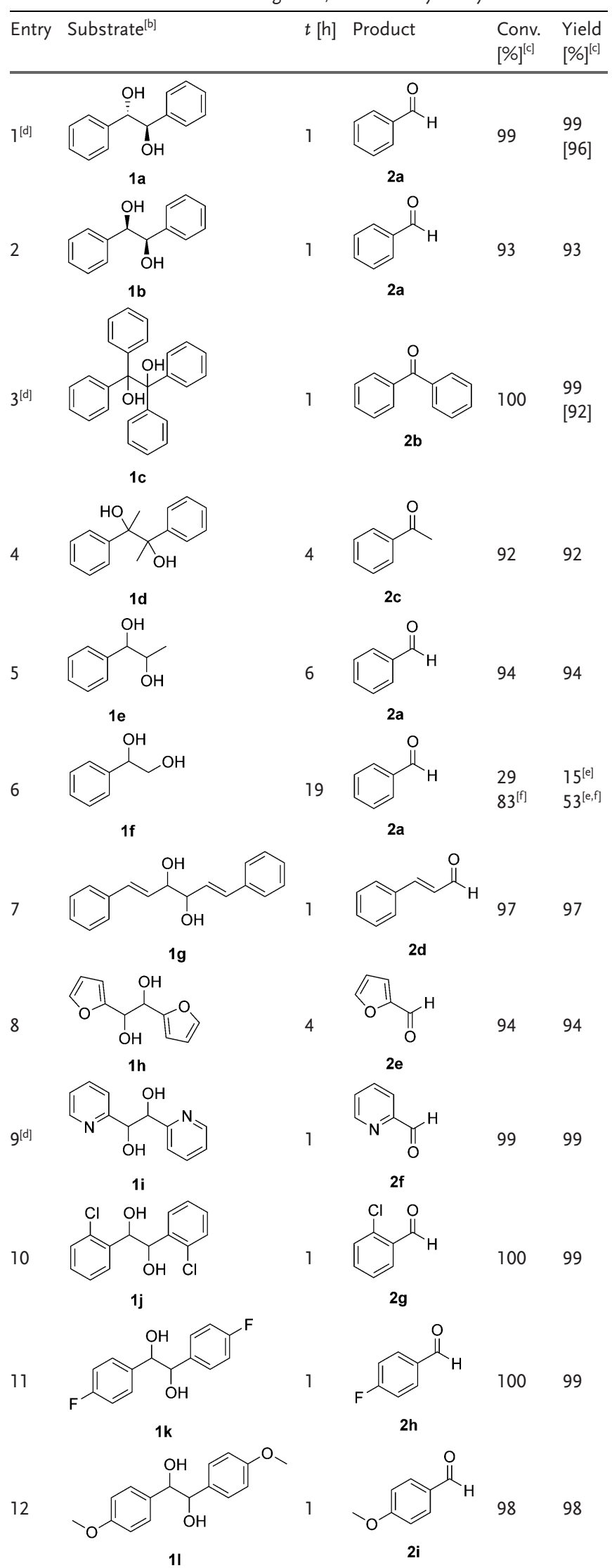


Table 2: (Continued)

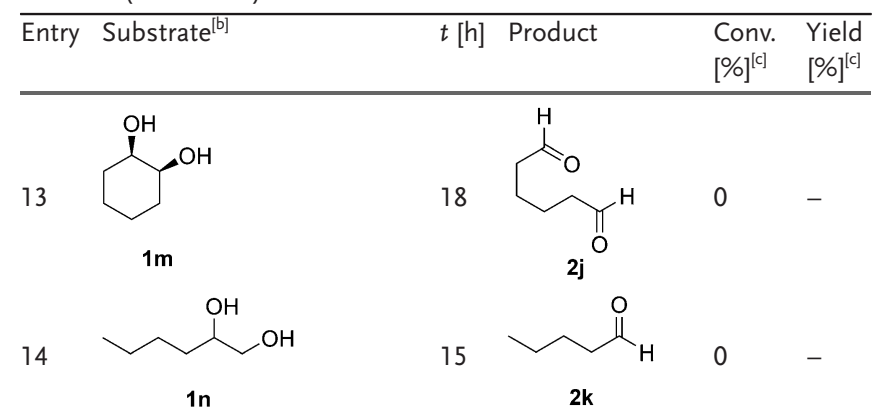

[a] Reaction conditions: substrate $(0.2 \mathrm{mmol}), \mathrm{Na}-\mathrm{Mn}$ LMO $(10 \mathrm{~mol} \%$ $\mathrm{Mn})$, 1-butanol $(1 \mathrm{~mL}), \mathrm{O}_{2}$ balloon, $100^{\circ} \mathrm{C}$. [b] Unless specified, the starting diols bearing two stereogenic centers were used as variable mixtures of diastereoisomers. [c] Determined by GC using dodecane as internal standard, values in square brackets correspond to isolated yields. Unless specified, remaining mass balance is recovered starting materials. [d] Reaction performed with 1 mol\% Mn from Na-Mn LMO. [e] Remaining mass balance was unidentified degradation products. [f] Reaction performed in presence of $\mathrm{Na}_{2} \mathrm{CO}_{3}(0.4 \mathrm{mmol})$.

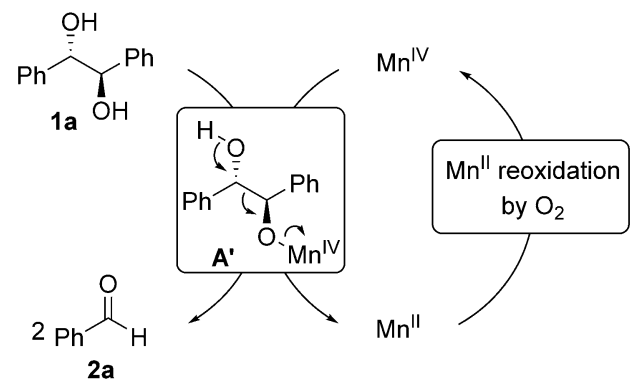

Scheme 2. Proposed mechanism for the reaction.

through an antiperiplanar geometry intermediate (see Scheme 2, $\mathbf{A}^{\prime}$ ) which would line up both $\mathrm{C}-\mathrm{O}$ sigma orbitals to facilitate the cleavage transition while minimizing the steric hindrance from the phenyl groups. ${ }^{[24]}$ Although less common, the higher reaction rate of anti-diol cleavage compared to its syn isomer has been observed and accounted for with the mechanism described. ${ }^{[25]}$ Based on this monodentate type II mechanism, two scenarios were possible: either a radical or a two-electron oxidative fragmentation. ${ }^{[2 a]}$ Such mechanistic investigations were previously performed on $\mathrm{Ce}^{\mathrm{IV}}$ reagents with the same substrate, and the two mechanisms were distinguished by addition of acrylamide for radical trapping. ${ }^{[2]}$ Since our experiments showed no difference in the presence or absence of acrylamide (Figure S12), we therefore conclude that the reaction catalyzed by Na-Mn LMO followed a type II mechanism via two-electron oxidative fragmentation as proposed in Scheme 2. This monodentate mechanism also supports the beneficial role of $\mathrm{Na}_{2} \mathrm{CO}_{3}$ observed for less-reactive substrates (Table 2, entry 6), which fosters deprotonation

1a of the $\mathbf{A}^{\prime}$ intermediate, as mentioned by Criegee et al. for this pathway. ${ }^{[27]}$ The proposed catalytic cycle involves $\mathrm{Mn}^{\mathrm{IV}}$ and $\mathrm{Mn}^{\mathrm{II}}$ species, with the $\mathrm{Mn}^{\mathrm{II}}$ species reoxidized by $\mathrm{O}_{2}$, forming $\mathrm{H}_{2} \mathrm{O}$. The fractional order of $\mathrm{O}_{2}$ suggests reoxidation of $\mathrm{Mn}^{\mathrm{II}}$ was part of the rate-determining step, and also indicates a sequence of elementary steps, possibly involving dissociation processes on the catalyst surface. ${ }^{[28]}$ Thus, current effort is devoted to investigate the reoxidation of $\mathrm{Mn}^{\mathrm{II}}$ into $\mathrm{Mn}^{\mathrm{IV}}$, on the catalyst surface. ${ }^{[2]}$ Such understanding would enable us to design the next generation of catalyst that could yield comparable performance using air, which displays a lower rate than pure $\mathrm{O}_{2}$ with our current $\mathrm{Na}-\mathrm{Mn}$ oxide catalyst, as Table 1 shows.

As the heterogeneous nature of the catalyst was a key attribute, it was assessed by the removal of the catalyst before the reaction was complete by simple filtration. Analysis of the reaction mixture showed no further conversion after removal of the catalyst (Figure S13). The recyclability of Na-Mn LMO catalyst was also confirmed. It was isolated, washed with ethanol and dried at $105^{\circ} \mathrm{C}$ for $2 \mathrm{~h}$ before being reused (Figure S14). The catalyst was employed in six successive runs without any loss of activity.

Finally, to further assess the utility of Na-Mn LMO catalysis as a synthetic tool, we examined its utility in multistep, one-pot reaction sequences. A set of diverse domino reactions involving an initial oxidative cleavage of 1,2-diol by Na-Mn LMO were conducted (Scheme 3), and all processes afforded the desired products with high efficiency, indicating the broad applicability of the catalyst.

In conclusion, we have developed a new method for the aerobic oxidative cleavage of 1,2-diols, with a heterogeneous catalyst, easily prepared from inexpensive and abundant metals. This catalyst affords the products in short reaction times, under mild conditions and with facile work-up, and can be reused several times without loss of activity. The absence of precious metals, toxic solvents and reagents, the use of $\mathrm{O}_{2}$ or air in atmospheric conditions with $\mathrm{H}_{2} \mathrm{O}$ as the only byproduct, make this catalyst more appealing for the cleavage of activated 1,2-diols to any previously reported systems. This
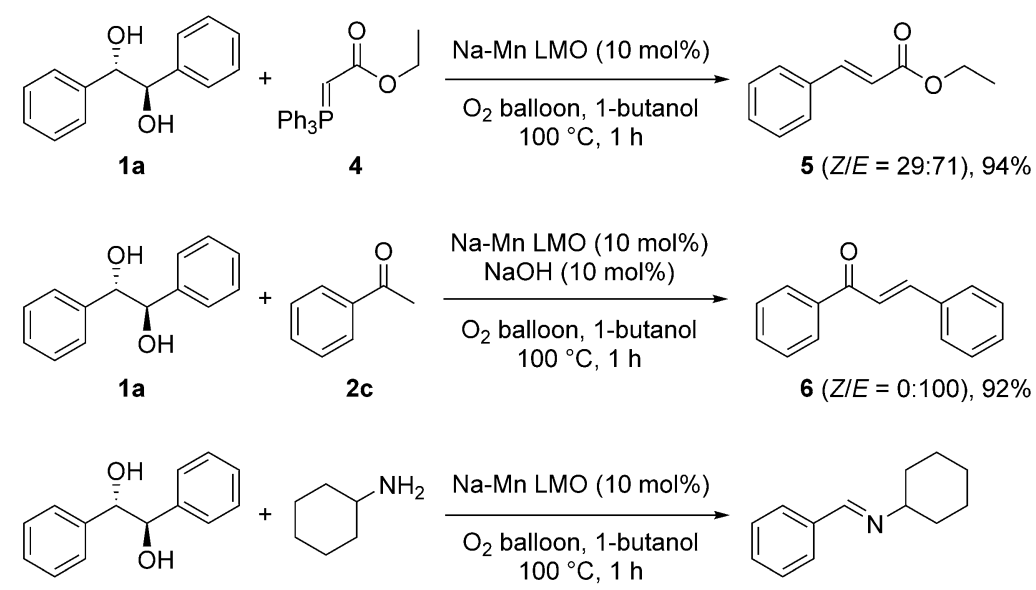

7

$8(Z / E=0: 100), 97 \%$

Scheme 3. Application of Na-Mn LMO-catalyzed aerobic oxidative cleavage of 1,2-diols in domino reactions. Yields and Z/E ratios were determined by ${ }^{1} H$ NMR spectroscopy. 
method excels at handling benzylic 1,2-diols, cleaved in excellent yields (92-99\%), with high selectivity (>99\%). Mechanistic investigations revealed a monodentate, twoelectron oxidative fragmentation, involving $\mathrm{Mn}^{\mathrm{IV}}$ as the oxidizing species. Finally, we applied this system in several domino reactions, showing the compatibility of the catalyst with different conditions to demonstrate its value as a powerful synthetic tool.

\section{Acknowledgements}

V.E. is grateful for support from French National Center for Scientific Research (CNRS). C.H.L. would like to thank the Donnelley Environmental Foundation for his fellowship support. Dr. Stephen Golledge from University of Oregon and Jinyang Li, from Prof. Dr. André Taylor's group at Yale University, are acknowledged for assistance with XPS and TG analysis, respectively. Dr. Sara Hashmi at the Facility for Light Scattering at Yale University is acknowledged for her assistance and instrumentation support.

\section{Conflict of interest}

The authors declare no conflict of interest.

Keywords: aerobic oxidation - cleavage reactions - diols . heterogeneous catalysis - manganese

[1] a) L. Malaprade, C. R. Hebd. Seances Acad. Sci. 1928, 186, 382 b) R. Criegee, Ber. Dtsch. Chem. Ges. B 1931, 64, 260.

[2] a) A. K. C. Schmidt, C. B. W. Stark, Synthesis 2014, 3283; b) A. W. H. Wong, T. K. M. Shing, in Comprehensive Organic Synthesis II, (Second Edition), Vol. 7 (Eds.: P. Knochel, G. A. Molander), Elsevier, Amsterdam, 2014, p. 801.

[3] a) D. S. Hage in Affinity Chromatography: Methods and Protocols (Eds.: P. Bailon, G. K. Ehrlich, W.-J. Fung, W. Berthold), Humana Press, Totowa, NJ, 2000, p. 69; b) A. Verdoliva, P. Bellofiore, V. Rivieccio, S. Catello, M. Colombo, C. Albertoni, A. Rosi, B. Leoni, A. M. Anastasi, R. De Santis, J. Biol. Chem. 2010, 285, 9090 .

[4] a) A. Behr, N. Tenhumberg, A. Wintzer, $R S C A d v$. 2013, 3, 172; b) F. Napoly, L. Jean-Gerard, C. Goux-Henry, M. Draye, B. Andrioletti, Eur. J. Org. Chem. 2014, 781; c) H. C. Zhu, Y. Zhang, X. G. Yang, H. Y. Liu, X. M. Zhang, J. M. Yao, Ind. Eng. Chem. Res. 2015, 54, 2825.

[5] a) P. T. Anastas, T. C. Williamson, D. Hjeresen, J. J. Breen, Environ. Sci. Technol. 1999, 33, 116A; b) "Green Chemical Syntheses and Processes": P. T. Anastas, L. G. Heine, T. C. Williamson in ACS Symposium Series, Vol 767 (Eds.: P. T. Anastas, L. G. Heine, T. C. Williamson), American Chemical Society, Washington, DC, 2000, p. 1.

[6] a) K. Yamaguchi, N. Mizuno, Chem. Eur. J. 2003, 9, 4353; b) K. Mori, T. Hara, T. Mizugaki, K. Ebitani, K. Kaneda, J. Am. Chem. Soc. 2004, 126, 10657; c) N. Obara, S. Hirasawa, M. Tamura, Y. Nakagawa, K. Tomishige, ChemCatChem 2016, 8, 1732.

[7] R. Mu, Z. Liu, Z. Yang, Z. Liu, L. Wu, Z.-L. Liu, Adv. Synth. Catal. 2005, 347, 1333.
[8] C. Klein-Koerkamp, R. Granet, R. Zerrouki, N. Villandier, F. Jérôme, J. Barrault, P. Krausz, Carbohydr. Polym. 2009, 78, 938.

[9] S. Riaño, D. Fernández, L. Fadini, Catal. Commun. 2008, 9, 1282.

[10] G. D. Du, L. K. Woo, J. Porphyrins Phthalocyanines 2005, 9, 206.

[11] M. Kirihara, K. Yoshida, T. Noguchi, S. Naito, N. Matsumoto, Y. Ema, M. Torii, Y. Ishizuka, I. Souta, Tetrahedron Lett. 2010, 51, 3619.

[12] a) V. Escande, E. Petit, L. Garoux, C. Boulanger, C. Grison, ACS Sustainable Chem. Eng. 2015, 3, 2704; b) V. Escande, C. H. Lam, C. Grison, P. T. Anastas, ACS Sustainable Chem. Eng. 2017, 5, 3214.

[13] a) J. L. G. Fierro, Metal oxides: chemistry and applications, Taylor \& Francis, Boca Raton, FL, 2006; b) H. F. Rase, Handbook of commercial catalysts: heterogeneous catalysts, CRC, Boca Raton, FL, 2000.

[14] G. B. Gerber, A. Leonard, P. Hantson, Crit. Rev. Oncol. Hematol. 2002, 42, 25.

[15] a) S. L. Suib, Acc. Chem. Res. 2008, 41, 479; b) B. Dutta, S. Biswas, V. Sharma, N. O. Savage, S. P. Alpay, S. L. Suib, Angew. Chem. Int. Ed. 2016, 55, 2171; Angew. Chem. 2016, 128, 2211; c) M. M. Najafpour, C. R. Chim. 2017, DOI: https://doi.org/10. 1016/j.crci.2015.12.009.

[16] J. Liu, J. P. Durand, L. Espinal, L.-J. Garces, S. Gomez, Y.-C. Son, J. Villegas, S. L. Suib in Handbook of layered materials (Eds.: S. M. Auerbach, K. A. Carrado, P. K. Dutta), Marcel Dekker, New York, 2004, p. 475.

[17] G. Ohloff, W. Giersch, Angew. Chem. Int. Ed. Engl. 1973, 12, 401; Angew. Chem. 1973, 85, 401.

[18] Q. Feng, K. Yanagisawa, N. Yamasaki, Chem. Commun. 1996, 1607.

[19] K. Kai, Y. Yoshida, H. Kageyama, G. Saito, T. Ishigaki, Y. Furukawa, J. Kawamata, J. Am. Chem. Soc. 2008, 130, 15938.

[20] J. T. Zhang, J. W. Jiang, X. S. Zhao, J. Phys. Chem. C 2011, 115, 6448.

[21] R. M. Potter, G. R. Rossman, Am. Mineral. 1979, 64, 1199.

[22] J. Luo, A. M. Huang, S. H. Park, S. L. Suib, C. L. O’Young, Chem. Mater. 1998, 10, 1561.

[23] a) D. H. R. Barton, J.-P. Finet, W. B. Motherwell, C. Pichon, Tetrahedron 1986, 42, 5627; b) W. T. Pennington, S. Chakraborty, I. C. Paul, D. Y. Curtin, J. Am. Chem. Soc. 1988, 110, 6498; c) A. S. Perlin in Advances in Carbohydrate Chemistry and Biochemistry, Vol. 60 (Ed.: H. Derek), Academic Press, New York, 2006, p. 183; d) A. M. Khenkin, R. Neumann, J. Am. Chem. Soc. 2008, 130, 14474.

[24] G. M. Rubottom in Oxidation in Organic Chemistry, Part D, Vol. 5 (Ed.: W. S. Trahanovsky), Academic Press, New York, 1982, p. 27.

[25] a) A. Goosen, H. A. H. Laue, J. Chem. Soc. B 1969, 995; b) W. S. Trahanovsky, J. R. Gilmore, P. C. Heaton, J. Org. Chem. 1973, 38, 760 ; c) E. S. Huyser, L. G. Rose, J. Org. Chem. 1972, 37, 851; d) A. M. Khenkin, R. Neumann, Adv. Synth. Catal. 2002, 344, 1017.

[26] a) G. Mino, S. Kaizerman, E. Rasmussen, J. Am. Chem. Soc. 1959, 81, 1494; b) W. S. Trahanovsky, L. H. Young, M. H. Bierman, J. Org. Chem. 1969, 34, 869.

[27] R. Criegee, E. Höger, G. Huber, P. Kruck, F. Marktscheffel, H. Schellenberger, Justus Liebigs Ann. Chem. 1956, 599, 81.

[28] P. L. Houston, Chemical kinetics and reaction dynamics, Dover Publications, Mineola, NY, 2006.

[29] V. D. Makwana, Y.-C. Son, A. R. Howell, S. L. Suib, J. Catal. 2002, 210, 46. 